\title{
A case report on near manual strangulation and glasgow coma scale.
}

\author{
Meel Banwari L.
}

Faculty of Health Sciences, Walter Sisulu University. P/bag X1, Mthatha, 5117, South Africa.

\begin{abstract}
Background: Glasgow Coma Scale (GCS) is considered as a gold standard in estimating the prognosis of the comatose patient. The management of the patient relies heavily on this scale. The mechanism of injury must also be included in scoring of the GCS. Survival from strangulation is uncommon, and if it occurs, it is often associated with various complications such as neurological consequences.

Objective: To highlight a poor correlation with low GCS and ultimate outcome in cases of manual strangulation.

Case report: This is a case report of young female adult who was raped and manually strangulated by a colleague during a training course for traditional healers. She was admitted with very low (3/15) Glasgow Coma Scale (GCS) and presumed to have a poor prognosis. She was rigorously ventilated in Intensive Care Unit (ICU), and was discharged from hospital after a week without any complications. The neck and genital injuries are described. This report discusses.

Conclusion: A low Glasgow Coma Scale is not a predictive of poor prognosis in cases of manual strangulation.

Keywords: strangulation, Glasgow coma scale, prognosis and resuscitation

DOI: http://dx.doi.org/10.4314/ahs.v15i3.45

Cite as: Meel Banwari L. A case report on near manual strangulation and glasgow coma scale. Afri Health Sci. 2015;15(3):1038-40. doi: bttp://dx.doi.org/10.4314/abs.v15i3.45
\end{abstract}

\section{Introduction}

Strangulation injuries account for approximately $2.5 \%$ of traumatic deaths worldwide. ${ }^{1}$ The hyoid is a thin, u-shaped bone in the neck just above the Adam's apple, which is very supple, pliable and bendable when a person is young, and is thus hard to fracture. It becomes calcified and brittle, as an individual gets older, so that it is more likely to fracture by the hands of an assailant. ${ }^{2}$ Ten percent of violent deaths in the U.S. each year are due to strangulation i.e squeezing the neck, (six females to every male). Strangulation or throttling is usually done with the hands, but notable variants include using the forearms, as when police officers used carotid restraint, and standing or kneeling on the victim's throat. ${ }^{3}$

GCS is a neurological scale, which aims to give a reliable, objective way of recording the conscious state of a person, for initial as well as continuing assessment. A patient is assessed against the criteria of the scale, and

\author{
Corresponding author: \\ Meel Banwari L. \\ Faculty of Health Sciences, \\ Walter Sisulu University. \\ P/bag X1, Mthatha, 5117, South Africa. \\ E-mail: bmeel@wsu.ac.za
}

the resulting points give a patient score between 3 (indicating deep unconsciousness) and either 14 (original scale) or 15 (the more widely used modified or revised scale). ${ }^{4}$

This case report highlights the fact that there is a poor correlation with low GCS and ultimate outcome.

\section{Materials}

This is a case report of rape and strangulation by the victim's colleague while they were attending training for traditional healers. The patient was examined in Accident and Emergency Department of Nelson Mandela Academic Hospital, Mthatha. Photographs were taken with the informed consent of a relative who accompanied the victim. Anonymity was kept for ethical reasons. $\mathrm{X}$-ray and CT scan were carried out in the hospital. Ethical approval was granted by the ethical committee of university No. 99/4114.

\section{Case history}

MT, a 23 years-old thinly built female was allegedly sexually assaulted on $8^{\text {th }}$ November 2007 while attending traditional healers' course in a group. She was found in a forest by her colleagues, partially naked, and in an unconscious state and gasping. Police was informed, and they brought her to Nelson Mandela Academic Hospital in a state of unconsciousness. The GCS was 3/15; pulse 123 beats/ minute; blood pressure was 106/80 $\mathrm{mm} \mathrm{Hg}$. She was not responding to verbal command, 
and deep sensory stimuli. There were no motor reflexes even after painful stimuli. Sub-conjunctival hemorrhages were noticed in both eyes; pupils were dilated and were not reactive to light.

On physical examination, there were multiple extensive bruises on both side of neck (Photograph 2 and 3).

She was having fits in the radiology department. On $\mathrm{X}$-ray and CT scan examination, there was a fracture of the left greater cornu of hyoid bone left side (Photograph 4). Ultrasound studies of neck were normal. There was also a stab wound $(3.5 \mathrm{~cm}$ X $1.5 \mathrm{~cm})$ on left side anterior axillary fold (Photograph 1).

On genital examination, there was no sign of injury, but vaginal introitus was bruised with redness. Hymen was old ruptured. Whitish discharge was seen which was collected in a swab, and preserved in a crime kit. The woman has survived and discharges after a week from ICU without any neurological deficit.

\section{Discussion}

Neck is a vulnerable to life-threatening compression injuries because of its contents such as trachea, spinal cord and blood vessels. Perpetrators of sexual assaults generally overpower women by compressing the neck with both hands, and therefore nail-mark or fingertips bruises are common in rapes.

By manual strangulation as in the case of MT, one could assume that the venous return was interrupted, so that congestive symptoms (congested of conjunctivae) were observed. At the same, arterial obstruction is also said to play an important role because loss of consciousness is reported to occur. ${ }^{5}$ Blood vessels and the trachea are occluded when sufficient pressure is applied on the neck. Only 11 pounds of pressure placed on both carotid arteries for ten seconds is necessary to cause unconsciousness. ${ }^{6}$ Forces of approximately $3.5 \mathrm{~kg}$ in adults are required to obstruct the carotid arteries, compared with approximately $2 \mathrm{~kg}$ for jugular veins. ${ }^{7}$ The difference is because of the fact that veins are lying more superficial than arteries. This is truer in thinly built female like MT, where neck muscles are thin.

In the case of MT, potentially fatal pressure was applied as the hyoid bone was fractured.

She was brought to Accident and Emergency Department in a state of deep coma with a 3/15 GCS, suggestive of application of a sufficient force to strangle her to death.

The neck also has very vital structures such as blood vessels and larynx, and the latter could suffer contusion in the process. However, there were no injuries noticed on ultrasound of the neck in this patient.

MT reached hospital after 10 hours. The emergency physician sedated and intubated her before transfer to ICU. She had fits in Radiology Department indicating cerebral hypoxia. Survival from strangulation is often associated with various complications including a large variety of neurological consequences. As it is common knowledge that the GCS and other initial presenting findings bear a poor correlation to the ultimate outcome, aggressive resuscitation and treatment of post-anoxic brain injury is indicated in every patient in absence of definite signs of death and irrespective of the duration of hypoxia or unconsciousness in cases of strangulation. ${ }^{8}$

MT was a victim of near-strangulation, homicidal in nature. This is surprising that she survived with completely dilated and unresponsive. pupils In addition, there were no motor reflexes even after painful stimuli, and only showed gasping.

There is a widespread agreement that death following strangulation ultimately occurs from cerebral hypoxia caused by compression of such a severe nature. Compression of carotid arteries can lead to ischemic neuronal death, which is also a mechanism leading to permanent brain damage in cases of near-strangulation with survival. ${ }^{9}$ Venous obstruction leads to cerebral stagnation, hypoxia, and unconsciousness, which in turn allow muscle tone relaxation, especially in the neck, which usually counters some of the pressure. ${ }^{1} \mathrm{MT}$ survived without any neurological deficit and one can assume that the time during which her central nervous system was without any oxygen must have been very short. This is because of the fact that she was strangulated manually, and perpetrator could not sustain uniform pressure on the neck structures such as airways, and blood vessels (in contrast of ligature strangulation). This is a "blessing in disguise" compared to ligature strangulation.

Thousands of women are raped and strangled each year in South Africa. The human neck is a uniquely vulnerable to life-threatening injuries especially during sexual assaults. Perpetrators generally overpower women by compression of the neck. This is because of the fact that neck is small in diameter, lacks bony shielding and is in close vicinity of vital structures such as trachea, spinal cord and blood vessels to and from the brain. 


\section{Conclusion}

This is a case of 'near- manual- strangulation' with low Glasgow- coma- scale and survival of victim without any neurological deficits. A low GCS and irrespective of duration of hypoxia or coma in cases of manual strangulation, aggressive resuscitation and treatment is indicated in every patient

\section{Acknowledgment}

The author would like to thank staff of the Radiology Department, and to Dr. George Rupesinghe for this manuscript.

\section{References}

1. Blank Reid C. Strangulation. RN 1999; 62:32-35 PubMed .

2. Baden M. HBO documentaries Home. Autopsy, 2008.http://www.hbo.com/autopsy/baden/qa_4.html (accessed 05.03.2008).
3. Maxam J. Missing Piece of Schiavo Puzzle. www. nothcoutrygazette.org/articles/062406schiavoPuzzle. html (Accessed 09.03.2008).

4. Wikipedia. Glasgow Coma Scale. Wikipedia.org/ wiki/Glasgow_Coma_Scale (accessed 25.05.2008).

5. Taylor AS. Taylor's Principles and practice of medical jurisprudence. Edinburgh: Churchill Livingstone; 1984. 6. Strack GB, McClane G. How to improve your investigation and prosecution of strangulation cases. J Forensic Sciences, 30:4, Oct 1985, 1140-47.

7. Rentoul E, Smith H. Glaistner's Medical Jurisprudence and Toxicology. Edinburgh: Churchill Livingstone; 1973.

8. Wahlen BM, Thierbach AR. Near hanging. Eur J Emerg Med. 2002; 9(4):348 PubMed -50.

9. Iserson KV. Strangulation: a review of ligature, manual and postural neck compression injuries. Ann Emerg Med 1984;13:179-85 PubMed 